\title{
Applications of Microscopy in Bacteriology
}

\author{
Mini Mishra1, Pratima Chauhan ${ }^{2 *}$ \\ ${ }^{1}$ Centre of Environmental Studies, Department of Botany, University of Allahabad, Allahabad, India \\ ${ }^{2}$ Department of Physics, University of Allahabad, Allahabad, India \\ Email:mishramini5@gmail.com, "mangu167@yahoo.co.in
}

Received 28 September 2015; accepted 2 January 2016; published 5 January 2016

Copyright ( 2016 by authors and Scientific Research Publishing Inc.

This work is licensed under the Creative Commons Attribution International License (CC BY).

http://creativecommons.org/licenses/by/4.0/

(c) () Open Access

\begin{abstract}
Bacteria are smallest primitive, simple, unicellular, prokaryotic and microscopic organisms. But these organisms cannot be studied with naked eyes because of their minute structure. Therefore in search for the information about the structure and composition of bacterial cells, cell biologist used light microscopes with a numerical aperture of 1.4 and using wavelength of $0.4 \mu \mathrm{m}$ separation. But there are still certain cellular structures that cannot be seen through naked eyes, and for them electron microscope is used. There are certain improved types of light microscope which can be incorporated to improve their resolving power. Hence microscopy is playing a crucial role in the field of bacteriology.
\end{abstract}

\section{Keywords}

\section{AFM, SEM, TEM, Microscopy, Bacteriology}

\section{Introduction}

To get acquainted with the world of bacteria like small organisms, very effective and advanced technique is required. The size of bacteria ranges between 0.5 - 5.0 micrometer in length; the smallest of them are members of mycoplasma which measures 0.3 micrometers [1]. Study of morphology and physiology of bacteria is called bacteriology which includes a large group of typically unicellular prokaryotic and eukaryotic bacteria widely distributed in air, water, soil etc. and therefore bacteriology requires many varied techniques and instruments. Microscopy is a great achievement in this respect [2] [3]. Microscopy promises to be a valuable tool for diagnosing and measuring the bacterial cell surfaces. The invention of the microscope opened the door to another world for scientists to pass through to look at organisms or things too small to be seen by the naked eye. The technical concept of using microscopes for the study of such small samples like bacteria etc. is said to be microscopy. Bacteriology as well as microscopy goes parallel side by side. Microscopy in the field of bacteriology in-

*Corresponding author.

How to cite this paper: Mishra, M. and Chauhan, P. (2016) Applications of Microscopy in Bacteriology. Microscopy Research, 4, 1-9. http://dx.doi.org/10.4236/mr.2016.41001 
cludes bright field, dark field, Atomic Force Microscopy, SEM, TEM, etc. [4]-[8]. Microscopy proved as a boon to find and identify causal bacteria and analyze samples to diagnose disease in organism. Microscopic detection of organism stained with different antibodies labeled with fluorescent dyes or other markers has proved to be very useful for specific identification of bacteria [9]. Here in this chapter we have reviewed about different microscopic techniques to study morphological as well as physiological characteristic of various bacterial strains. Electron microscopy surpasses the use of light microscopy due to high resolution power and hence transmission electron microscopy becomes important to find number of bacterial cells and their biomass [8] [10]. Recent advancements in microscopy lead to the invention of Atomic Force Microscopy and Scanning Probe microscopy which is evolving from a qualitative imaging tool to quantitative probe of interaction forms to characterize the properties and function of unicellular prokaryotes [11]. Atomic force microscopy overcame the challenge of sample preparation by using contact mode-AFM to study cell growth and division of AFM [12].

\section{Microscopy}

Microscopy is the technical field of using microscopes to view samples and objects that cannot be seen with the unaided eye (objects that are not within the resolution range of the normal eye). Microscopy is all about seeing, and seeing things with greater knowledge and insight. Microscopy is based on two major principles:

1) Resolution and resolving power-Resolution and resolving power of a microscope is defined as the minimum distance by which 2 points must be separated in order for them to be perceived as to separate point rather than a fused image.

2) Magnification-Linear magnification refers to the ratio of image length to object length measured in planes that are perpendicular to the optical axis. A negative value of linear magnification denotes an inverted image. Longitudinal magnification denotes the factor by which an image increases in size, as measured along the optical axis [13].

There are three well-known branches of microscopy: optical, electron, and scanning probe microscopy. Conventional optical microscopy uses an instrument consisting of one or more lenses that produce an enlarged image of an object placed in the focal plane of lense. Its resolution limit for submicron particles is within visible light i.e. 400 to $700 \mathrm{~nm}$. Optical microscopy is applicable to observe crystal morphology and symmetry as well as identifying phase, purity and homogeneity. Electron microscopy has long been recognized as a key technique in microbiology to elucidate cell surface ultra structure [14]. Optical and electron microscopy involve the diffraction, reflection, or refraction of electromagnetic radiation/electron beams interacting with the specimen, and the subsequent collection of this scattered radiation or another signal in order to create an image. This process may be carried out by wide-field irradiation of the sample (for example standard light microscopy and transmission electron microscopy) or by scanning of a fine beam over the sample (for example confocal laser scanning microscopy and scanning electron microscopy) [15]. Because of the small size of microorganisms, the physical properties of their surfaces have been difficult to study with conventional methods of microscopy hence there is clearly a need for new, nondestructive tools capable of probing single cell surfaces at high resolution. During the last years, atomic force microscopy (AFM). The most recent advance technique in AFM is reported the use of force distance based technology to simultaneously image the structure and maps the biophysical properties of biological samples at the nanoscale range [16].

\section{Bacteriology}

The branch of biology that deals with the study of morphology, physiology and cytology of bacterial strains is said to be bacteriology. The beginning of bacteriology paralleled the development of microscopy. The modern methods of bacteriological techniques begin in 1870-85with the introduction of the use of stains and by the discovery of the method of separating mixtures of organisms on plates of nutrient media solidified with gelatin or agar. Bacteria are prokaryotes and have no nucleus, rather there is a genetic material restricted to an area of cytoplasm called nucleoid. Prokaryotic cells do not have cytoplasmic compartments such as mitochondria and lysosomes. These cells differ in complexity and hence bacteria are divided into two major groups, the gram negative and gram-positive organism, which reflects their cell wall structure. Gram-positive bacteria is relatively thick and featureless contains peptidoglycan which comprises $50 \%$ of major componentbut have no lipid and often no protein content, accessory polymers like teichoic acid are covalently linked to peptidoglycan. On the other hand, gram-negative cells consist of a pair of membrane with thin intermediate layer of peptidoglycan. The 
outer membrane contains lipopolysaccharide as well as lipids and proteins. LPS is located exclusively in the outer leaflet, lipid embedded in the membrane, polysaccharide protruding. This makes the bacteria appear rather fuzzy under electron microscope [1]. There are more than thousand species of bacteria, but all of them are basically of three different shapes, some are like little balls and called cocci, others are still helical or spiral in shape, like Borrelia, Some bacterial cells exist as individuals while others cluster together to form pairs, chains, squares or other groupings. Some are rod- or stick-shaped and called bacilli. The external form and structure of bacteria including shape, size and arrangement of bacteria is a defining charecteristics called morphology. Bacteria grow and spread widely with variety of size and shape. The most common are rods (Bacilli) and spheres (cocci) [17].

\subsection{Microscopic Study of Bacteria}

The typical compound microscope has objective that face downwards and pick up light that is transmitted through the biological specimen on the microscope slide. This is different from the tissue culture microscope that is made especially for viewing cell cultures grown in petri dishes. This type of microscope has inverted objectives that are under the petri dish and face upward to the Petri dish where the culture first begins to grow. Both use transmitted light microscopy where the light is passed through the specimen. Other methods of viewing bacteria and culture smears may entail the use of the phase contrast microscope. Using phase is often the method of choice when it is desired to not stain the fresh bacterial strain.

\subsection{Sample Preparation for the Study through Microscope}

Living bacteria are difficult to observe under microscope directly for the reason that they are of very small dimensions and most bacteria are colorless hence there is utmost need to prepare bacterial samples in such a way so as to make them visible under microscope.

\subsubsection{Fixation}

It is the first step in sample preparation and has the aim of preserving tissue in its original state. Specimens for light and electron microscopy are commonly fixed with a solution containing chemical that crosslink most proteins and nucleic acid. Fixatives are acids and aldehydes such as acetic acid, picric acid, formaldehyde, and glutaraldehyde. $\mathrm{OsO}_{4}$ vapours used for preparing samples for SEM analysis [18].

\subsubsection{Staining}

Most biological materials show little contrast with their surrounding unless they are strained. In the case of light microscopy, contrast can be enhanced by using colored stains which selectively absorbed certain wavelength. Specimens for light microscopy are stained to visualize the structural features. Many chemical stains bind to specific molecules present in the specimen. For example, hematoxylin, bind to basic amino acid (lysine and arginine) of different proteins, whereas eosin binds to acidic molecules such as DNA and side chains of asparatate and glutamate) [18].

Although unstained, amorphous, frozen-hydrated sections provide a faithful, high-resolution representation of living material, the observation of unstained frozen-hydrated Specimens provides a unique method for the measurement of density [19] [20].

\subsubsection{Washing}

After staining the sample is washed by several buffer solutions specifically, like washing with double distilled water or in a $1 \%$ solution of ammonium acetate [21]. Another method for washing the samples for dark field microscopy uses nonfoaming spray-on glass cleaner such as Bon-Ami, which is wiped off with tissue after a few seconds, to be as effective as acid washing procedures [4].

\subsubsection{Dehydration}

After fixing and washing the specimens are dehydrated by number of alcoholic series. Dehydration is best performed in capped wide-neck vials to accommodate the filters. The specimens are dehydrated through a graded ethanol series ( 20 40, 60, 80, 95, 100, 100, 100\% ethanol) on a slowly moving inclined rotary table. Short, 5 - 10 min, intervals are sufficient to dehydrate several filters in a vial. Finally, the filters are critical-point dried [22]. The filter mustremain wet all the time. It may be transferred very briefly onto a piece of filter paper to drain re- 
sidual absolute ethanol before critical-point drying.

\subsection{Morphological Study of Bacteria through Different Microscopic Techniques}

There are various microscopic techniques which are employed in the field of bacteriology, for particular morphology, anatomy and physiology and various shapes and sizes of bacterial strains which is the basis for the identification of a particular bacteria and diagnosing diseases caused by pathogenic species.

\subsubsection{Through Atomic Microscopy (AFM)}

Atomic force microscopy (AFM) has been used increasingly to investigate microbial surfaces at high resolution. With AFM, the structure of isolated cell surface layers can now be imaged at sub molecular resolution [5]. By imaging bacteria in aqueous solution, AFM can provide real-time in situ quantitative morphological information as well as measurement of the interaction forces between AFM tip (and modified probe) and cell surface [10].

The morphological features of typical bacteria are very well studied by atomic force microscopy for example E. coli bacteria shows flat patched layer on the surface under AFM without rinsing the sample [23]. Through AFM it is rather much easier way to distinguish between gram negative and gram positive bacteria without anypretreatment to the sample. Light microscopy cannot be incorporated to study subcellular details such as murein like structures hence atomic force microscopy is used to measure elasticity and rigidity properties of bacterial surfaces and thickness of murein sacculi [24]. For example in Figure 1 AFM image of $E$. coli shows size of the cells [25].

\subsubsection{Through Electron Microscopy}

Electron microscopy is of two types—scanning electron microscopy and transmission electron microscopy:

\section{- Scanning electron microscopy:}

It is provided for producing a scan image at high spatial resolution and in a low acceleration voltage area. The electron beam is generally scanned in a raster scan pattern, and the beam's position is combined with the detected signal to produce an image. SEM can achieve resolution better than 1 nanometer. For SEM specimen is normally required to be completely dry, since the specimen chamber is at high vacuum. The pathogenicity of Vibrio cholera, a gram negative bacteria which causes cholera is still obscure. Electron microscopy revealed ultrastucture of bacteria in which nuclear Zone is clearly visible, and excretion of cell wall is also observed [6]. Histopathological investigation of Campylobacter pyloridis under scanning electron microscopy proved to be significant to diagnose the presence of pathogen in abnormal mucosa which is the cause of gastritis ulceration [26]. Electron microscopy revealed flagella and pilli in twenty one strains of Legionella pneumophilla [27]. In Figure 2, the two yeast cell Saccharomyces carlsbergenesis and S. cervisia shows double membrane cell wall by observing under electron microscope [28].

\section{- Transmission electron microscopy:}

In this type of microscopy a beam of electrons is transmitted through an ultra-thin specimen, interacting with the specimen as it passes through. An image is formed from the interaction of the electrons transmitted through the specimen; the image is magnified and focused onto an imaging device. Some temperature dependent bacteria L. monocytogens exhibit typical number of flagella seen by transmission electron microscopy [29]. Calcium

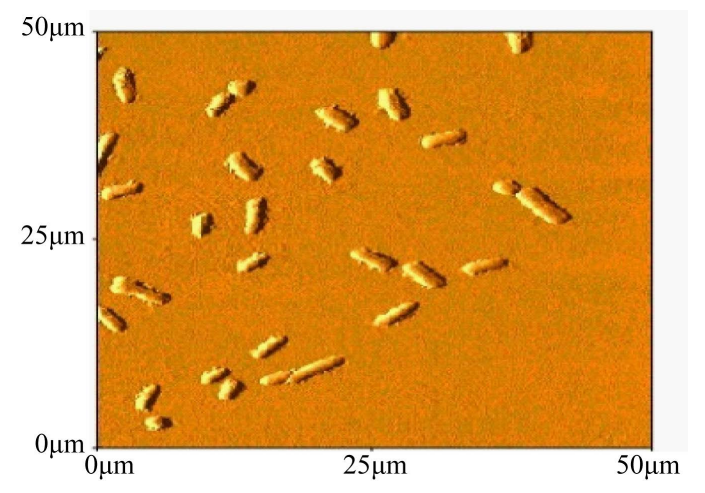

Figure 1. AFM image of Escherichia coli. 


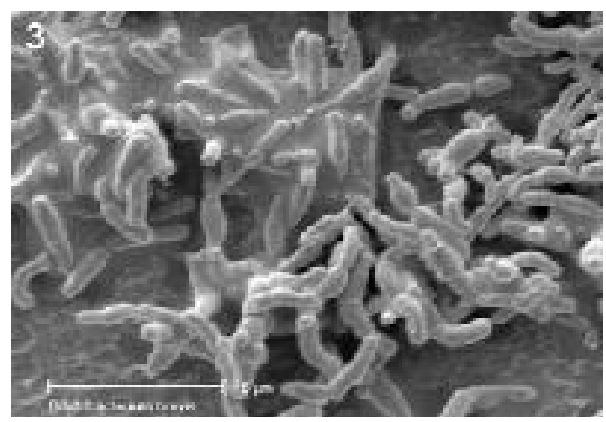

Figure 2. Scanning electron microscopic image of E. coli spores.

bilirubinate stones with bacterial infection were examined by transmission electron microscopy which shows the presence of mixed microcolonies of gram positive and gram negative bacteria embedded in an amorphous anionic matrix [22]. Conventional preparation for TEM has now been replaced by Cryo-TEM to measure and analyze thin cytoplasmic sections of certain bacteria in which high pressure freezing technique is used [19]. Thin section of E. coli bacteria can be observed by Transmission electron microscopy as seen in Figure 3 [30].

\subsubsection{Through Dark Field Microscopy}

Dark field microscopy is a technique used to observe unstained samples causing them to appear brightly against a dark, almost purely black, background. These specimens often have similar refractive indices as their surroundings, making them hard to distinguish with other illumination techniques. It works by illuminating the sample with light that will not be collected by the objective lens, and thus will not form part of the image. Flagellation of bacteria can be studied by dark field microscopy of individual unstained flagella on whole cell. $S$. typhimurium has peritrichous flagella and Pseudomonas species are polarly flagellated [4]. The ability to see individual, unstained flagella is a significant advance in the power of dark field light microscopy. Here in Figure 4 one can clearly see the flagella of bacteria through Dark field microscope.

\subsubsection{Through Epifluorescent Microscopy}

It works on the principle of fluorescence which is the property of some atoms and molecules to absorb light at a particular wavelength and to subsequently emit light of longer wavelength. It is especially useful to detect biological samples, locate spatial distribution of particular molecules in the structure. By using Epifluorescent microscopy number of bacterial cells can be counted as direct viable bacterial cells (DVC). In this technique sybr green fluorescent stain is used for bacterial count which results in accurate number of particles-associated as in Figure 5 [32].

\subsubsection{Scanning Laser Confocal Microscopy}

It is employed as effective tool to detect spatial distribution of bacteria in Rhizosphere. In this technique nondestructive optical sections of a sample are obtained and disturbing effect from out of focus fluorescence is reduced. Azospirillum brassitence found in Rhizosphere with SCLM and labeled rRNA probe [9]. For example in Figure 5 the laser reflects off the rock surfaces and shows up green. In Figure 6 the bacteria were dyed with a chemical and appear red in the laser light [33].

\subsection{Study of Nuclear Component through Microscopy}

Electron microscopy heteroduplex recognizes the presence of Insertion sequences on F and R plasmid in bacteria and these sequences on several phage DNA will form duplex region [34]. The structure of nuclear protein as well as nucleic acid is observed through different microscopic techniques. Di IVA protein structures observed in Bacillus subtilis during cell division under transmission electron microscopy in cryogenic stains [35].

\subsection{Physiology of Bacterial Cells through Microscopy}

Various physiological activities of bacterial cells can be very well studied microscopic techniques. Transmission 


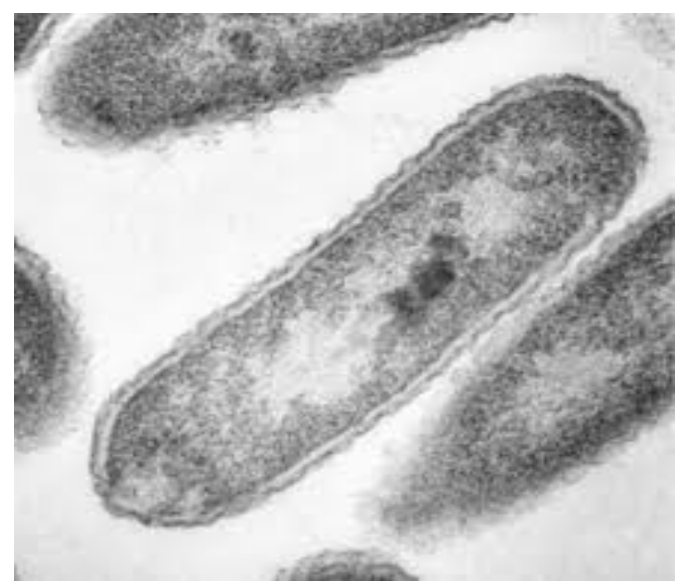

Figure 3. TEM image showing thin section of bacteria [30].

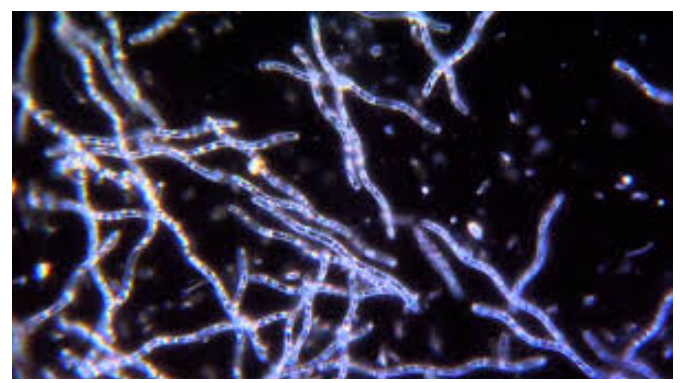

Figure 4. Dark field microscopy of bacterial colony [31].

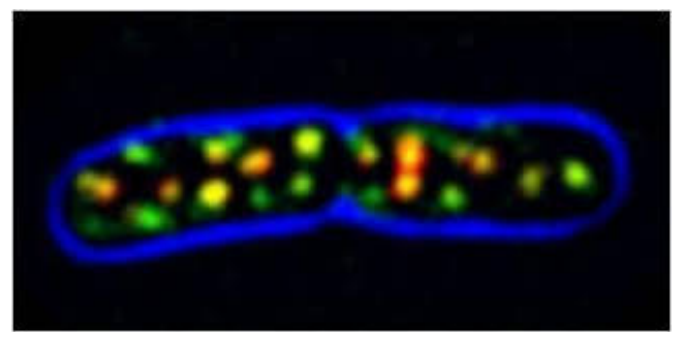

Figure 5. Epifourescent microscopy of bacteria.

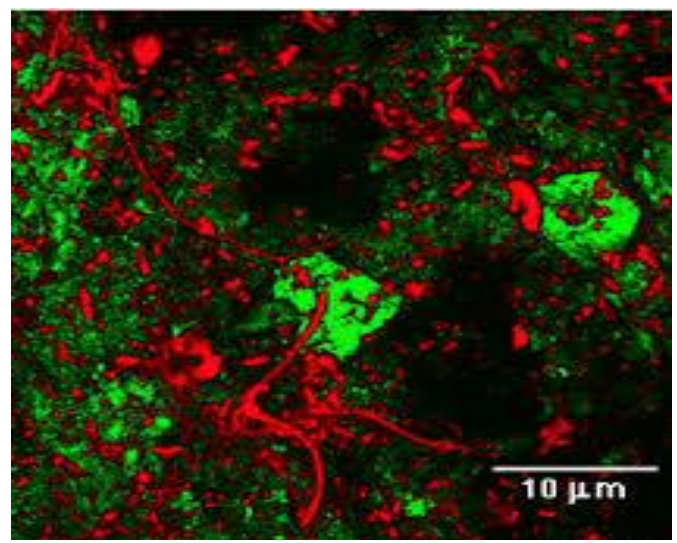

Figure 6. Scanning laser confocal microscop. 
electron microscopy has been previously used to study the Kinetics of granule formation and degradation [30]. The antimicrobial action of Melaleucaalternifolia oil on Staphylococcus aureus for three components 1, 8-cineole, terpinen-4-ol, and $\alpha$-terpinol was investigated by Electron Microscopy. Terpine-4-ol-treated S. aureus cells contained multilamellar, mesosomelike structures. The contents of some treated cells appeared depleted and amorphous [9]. Agrobacterium tumefaciens which causes crown gall disease is seen through scanning electron microscopy attached to monocots [36]. The antibacterial action of silver ions on E. coli studied by using a new and advance microscopic technique of energy filtering transmission electron microscopy in which the electron probe was focused to a full width at half maximum of $0.9 \mathrm{~nm}$ for elemental analysis using energy dispersive X-ray spectroscopy (EDX) [37].

\section{Conclusions}

Since the beginning of microbiology by the discovery of bacteria, a new era of microscopic technique has also been developed. Because it cannot be possible to observe such a small creatures like bacteria through our naked eyes.

Previously used microscopes were simple light microscope but there came a lot of difficulty in observing submicron particles through light microscope and after that electron microscopy came into existence which had revolutionized the microbial world with the identification of nuclear component of bacterial cells. After that more advance technique named Atomic force Microscopy (AFM) overcame with all the difficulty in the study of ultrathin structures of bacterial cells as it could provide real time in situ quantitative morphological information.

Much recent microscopic techniques are Epifluorescent Microscopy, Scanning Laser Confocal Microscopy etc. The difference between different microscopic techniques is based on source of transmission on the object.

\section{Acknowledgements}

We would like to acknowledge the academic section of university of Allahabad for providing liberary and internet facilities to scan the literature regarding the review, we are thankful to the central facilities of the department. Great vote of thanks to our labmates who gave their precious ideas and valuable time to make this review worth. Financial support was provided by UGC fellowship and contingency.

\section{References}

[1] Toder, K. (2012) Online Textbook of Bacteriology. www.textbookofbacteriology.net

[2] Beveridge, T.J. and Graham, L.L. (1991) Surface Layers of Bacteria. Microbiological Reviews, 55, 684-705.

[3] Beveridge, T.J. (1999) Structures of Gram-Negative Cell Walls and Their Derived Membrane Vesicles. Journal of Bacteriology, 181, 4725-4733.

[4] Macnab, R.M. (1976) Examination of Bacterial Flagellation by Dark-Field Microscopy. Journal of Clinical Microbiology, 4, 258.

[5] Dufrene, Y.F. (2003) Atomic Force Microscopy, a Powerful Tool in Microbiology. Current Opinion in Microbiology, 6, 317-323. http://dx.doi.org/10.1016/S1369-5274(03)00058-4

[6] Chatterjee, S.N. and Das, J. (1967) Electron Microscopic Observations on the Excretion of Cell-Wall Material by Vibriuchulerae. Journal of General Microbiology, 49, 1-11. http://dx.doi.org/10.1099/00221287-49-1-1

[7] Shapiro, J.A. (1985) Scanning Electron Microscope Study of Pseudomonasputida Colonies. Journal of Bacteriology, 164, 1171-1181.

[8] Borsheim, K.Y., Bank, G.B. and Heldal, M. (1990) Enumeration and Biomass Estimation of Planktonic Bacteria and Viruses by Transmission Electron Microscopy. Applied and Environmental Microbiology, 56, 352-356.

[9] Assmus, B., Hutzler, P., Kirchhof, G., Amann, R., Lawrence, J.R. and Hartmann, A. (1995) In Situ Localization of Azospirillum brasilense in the Rhizosphere of Wheat with Fluorescently Labeled, rRNA-Targeted Oligonucleotide Probes and Scanning Confocal Laser Microscopy. Applied and Environmental Microbiology, 61, 1013-1019.

[10] Kogure, K., Simidu, U. and Taga, N. (1979) A Tentative Direct Microscopic Method for Counting Living Marine Bacteria. Canadian Journal of Microbiology, 25, 415-420. http://dx.doi.org/10.1139/m79-063

[11] Colton, R.J., Baselt, D.R., Dufrkne, Y.F., Green, J.-B.D. and Lee, G.U. (1997) Scanning Probe Microscopy. Current Opinion in Chemical Biology, 1, 370-377. http://dx.doi.org/10.1016/S1367-5931(97)80076-2

[12] Touhami, A., Jericho, M.H. and Beveridge, T.J. (2004) Atomic Force Microscopy of Cell Growth and Division in Sta- 
phylococcus aureus. Journal of Bacteriology, 186, 3286-3295. http://dx.doi.org/10.1128/JB.186.11.3286-3295.2004

[13] Cappucino, J.G. and Sherman, N. (1998) Microbiology: A Laboratory Mannual. 5th Edition, Cumming Science Publishing, New York.

[14] Kalab, M., Yang, A.-F. and Chabot, D. (2008) Conventional Scanning Electron Micrscopy of Bacteria. Infocus, Issue 10.

[15] Jian, J., Sinkey, A.J. and Stubbe, J.A. (2005) Kinetic Studies of Polyhydroxybutyrate Granule Formation in Wautersia eutropha H16 by Transmission Electron Microscopy. Journal of Bacteriology, 187, 3814-3824. http://dx.doi.org/10.1128/JB.187.11.3814-3824.2005

[16] Binnig, G., Quate, C.F. and Gerber, C. (1986) Atomic Force Microscope. Physical Review Letters, 56, 930-933. http://dx.doi.org/10.1103/PhysRevLett.56.930

[17] Dr Boa, A.N. (1995) The Bacterial Cell Wall. Module 06763, Department of Chemistry, University of Hull, Kingston upon Hull.

[18] Jones, H.C., Roth, I.L. and Sanders, W.M. (1969) Electron Microscopic Study of a Slime Layer. Journal of Bacteriology, 99, 316-325.

[19] Matrias, V.R.F., Al-Amoudi, A., Dubochet, J. and Beveridge, T.J. (2003) Cryo-Transmission Electron Microscopy of Frozen-Hydrated Sections of Escherichia coli and Pseudomonas aeruginosa. Journal of Bacteriology, 185, 6112-6118. http://dx.doi.org/10.1128/JB.185.20.6112-6118.2003

[20] Sleytr, U.B. (1975) Heterologous Reattachment of Regular Arrays of Glycoproteins on Bacterial Surfaces. Nature, 257, 400-402. http://dx.doi.org/10.1038/257400a0

[21] Umeda, A., Saito, M. and Amako, K. (1998) Surface Charecteristic of Gram-Negative and Gram-Positive Bacteria in an Atomic Force Microscope Image. Microbial Immunology, 42, 159-164. http://dx.doi.org/10.1111/j.1348-0421.1998.tb02266.x

[22] Leung, J.W.C., Sung, J.Y. and Costeroton, J.W. (1989) Bacteriological and Electron Microscopy Examination of Brown Pigment Stones. Journal of Clinical Microbiology, 27, 915-921.

[23] Bolshakova, A.V., Kiselyova, O.I., Filonov, A.S., Frolova, O.Y., Lyubchenko, Y.L. and Yaminsky, I.V. (2001) Comparative Studies of Bacteria with an Atomic Force Microscopy Operating in Different Modes. Ultramicroscopy, 86, 121-128. http://dx.doi.org/10.1016/S0304-3991(00)00075-9

[24] Yao, X., Jericho, M., Pink, D. and Beveridge, T. (1999) Thickness and Elasticity of Gram-Negative Murein Sacculi Measured by Atomic Force Microscopy. Journal of Bacteriology, 181, 6865-6875.

[25] Osiro, D., Filho, R.B., Assis II, O.B.G., de Castro Jorge II, L.A. and Colnago, L.A. (2012) Measuring Bacterial Cells Size with AFM. Brazilian Journal of Microbiology, 43, 341-347. http://dx.doi.org/10.1590/s1517-83822012000100040

[26] Price, A.B., Jean, L.J., Dolby, M., Dunscombe, P.L., Smith, A., Clerk, J. and Stephenson, M.L. (1985) Campylobacter Pyloridis in Peptic Ulcer Disease Microbiology, Pathology and Scanning Electron Microscopy. Gut, 26, 1183-1188. http://dx.doi.org/10.1136/gut.26.11.1183

[27] Rodgers, F.G., Greaves, P.W., Macrae, A.D. and Lewis, M.J. (1980) Electron Microscopic Evidence of Flagella and Pili on Legionella pneumophilla. Journal of Clinical Pathology, 33, 1184-1188.

http://dx.doi.org/10.1136/jcp.33.12.1184

[28] Kaláb, M. and Yang, A.F. Mounting Bacteria on SEM Stubs for Long-Term Preservation. http://www.usu.edu/westcent/microstructure food/Sticky tape.htm

[29] Bartholomew, J.W. and Levin, R. (1955) The Structure of Saccharomyces carlsbergensis and S. cerevisiaeas Determined by Ultra-Thin Sectioning Methods and Electron Microscopy. Journal of General Microbiology, 12, 473-477. http://dx.doi.org/10.1099/00221287-12-3-473

[30] Sanchez-Pescador, R., Stempien, M.S. and Urdea, M.S. (1988) Rapid Chemiluminescent Nucleic Acid Assays for Detection of TEM-1 Beta-Lactamase-Mediated Penicillin Resistance in Neisseria gonorrhoeae and Other Bacteria. Journal of Clinical Biology, 26, 1934-1938.

[31] Peel, M., Donachie, W. and Shaw, A. (1988) Temperature-Dependent Expression of Flagella of Listeria manocytogenes Studied by Electron Microscopy, SDS-PAGE and Western Blotting. Journal of General Microbiology, 134, 2171-2178. http://dx.doi.org/10.1099/00221287-134-8-2171

[32] Lunao, M., Walther, A.L.K., Martens-Habbena, W. and Simon, M. (2005) An Improved Method for Counting Bacteria from Sediments and Turbid Environments by Epifluorescence Microscopy. Environmental Microbiology, 7, 961-968. http://dx.doi.org/10.1111/j.1462-2920.2005.00767.x

[33] Jeffery, T.G. (1996) Life Underground. PSR Discoveries.

[34] Hu, S., Ohtsubo, E., Davidson, N. and Saedler, H. (1975) Electron Microscope Heteroduplex Studies of Sequence Re- 
lations among Bacterial Plasmids: Identification and Mapping of the Insertion Sequences IS1 and IS2 in F and R Plasmids. Journal of Bacteriology, 122, 764-775.

[35] Stahlberg, H., Kutejova, E., Muchova, K., Gregorini, M., Lustig, A., Muller, S.A., Olivieri, V., Engel, A., Wilkinson, A.J. and Barak, J. (2004) Oligomeric Structure of the Bacilus subtilis Cell Division Protein DivIVA Determined by Transmission Electron Microscopy. Molecular Microbiology, 52, 1281-1290. http://dx.doi.org/10.1111/j.1365-2958.2004.04074.x

[36] Carson, C.F., Mee, B.J. and Riley, T.V. (2002) Mechanism of Action of Melaleuca alternifolia (Tea Tree) Oil on Staphylococcus aureus Determined by Time-Kill, Lysis, Leakage, and Salt Tolerance Assays and Electron Microscopy. Antimicrobial Agents and Chemotherapy, 46, 1914-1920. http://dx.doi.org/10.1128/AAC.46.6.1914-1920.2002

[37] Yamanaka, M., Hara, K. and Kudo, J. (2005) Bactericidal Actions of a Silver Ion Solution on Escherichia coli, Studied by Energy-Filtering Transmission Electron Microscopy and Proteomic Analysis. Applied and Environmental Microbiology, 71, 7589-7593. http://dx.doi.org/10.1128/AEM.71.11.7589-7593.2005 